\title{
Effect of General and Non-general Anesthesia on Postoperative Cognitive Dysfunction
}

\author{
Yue $\mathrm{Gao}^{1}$, Lian Liư', Bo Zhao², Yafeng Wang², Shihua Yu and Huaxin Wang ${ }^{2}$ \\ ${ }^{1}$ Department of Personnel, Renmin Hospital of Wuhan University, Wuhan, China \\ ${ }^{2}$ Department of Anesthesiology, Renmin Hospital of Wuhan University, Wuhan, China \\ ${ }^{3}$ Department of Anesthesiology, Renmin Hospital of Hannan District, Wuhan, China
}

\begin{abstract}
ABATRACT
Controversy exists in the effect of general anesthesia and non-general anesthesia on postoperative cognitive dysfunction (POCD). The authors aimed to perform this systematic review to comprehensively assess the effect of general anesthesia or non-general anesthesia on POCD. Relative studies from the online literature database were retrieved. Seven studies with 1,031 patients were included. Odds ratio and 95\% confidence interval were calculated. The results showed that the POCD incidence was significantly lower in the patients underwent non-general anesthesia than those underwent general anesthesia in one and three days after surgery $(p<0.05)$. However, no remarkable difference existed between the two anesthesia in seven days and three months after surgery $(p>0.05)$. In conclusion, when compared with the non-general anesthesia, general anesthesia increases the incidence of POCD in patients within three days after surgery, but makes no difference after seven days. It suggests that early intervention should be conducted on patients undergoing general anesthesia.
\end{abstract}

Key Words: General anesthesia, Postoperative cognitive dysfunction, Meta-analysis.

How to cite this article: Gao Y, Liu L, Zhao B, Wang Y, Yu S, Wang H. Effect of General and Non-general Anesthesia on Postoperative Cognitive Dysfunction. J Coll Physicians Surg Pak 2020; 30(04):407-411. DOI: https://doi.org/10.29271/jcpsp.2020.04.407.

\section{INTRODUCTION}

Postoperative cognitive dysfunction (POCD) is one of the most common complications of postoperative patients and it is also one of the hot researches in anesthesiology and neurocognition. ${ }^{1,2}$ The cerebral cortex is the basis of cognition, and any factors that cause functional abnormalities in the cerebral cortex can lead to cognitive dysfunction. ${ }^{3,4}$ The clinical manifestations of POCD can vary from mild cognitive abnormalities to severe memory impairment, such as loss of judgment, personality changes and so on, which are considered as the early stage of Alzheimer's disease. ${ }^{5,6}$ If therapeutic intervention is given in the stage of mild cognitive impairment, it may be possible to reduce or delay the incidence of Alzheimer's disease. $^{7}$

Age is the only widely accepted risk factor in the development of POCD. ${ }^{8}$ however, the effect of anesthesia on the incidence of POCD has still been inconsistent and controversial. Some studies reported that general anesthesia may be the cause of POCD, ${ }^{9}$ but there were some otherstudies which consider that general anesthesia makes no significant difference in the occurrence of POCD among postoperative patients. ${ }^{10}$

Correspondence to: Huaxin Wang, Department of Anesthesiology, Renmin Hospital of Wuhan University, Wuhan, China E-mail: whuaxin@163.com

Received: April 26, 2019; Revised: July 10, 2019;

Accepted: August 08, 2019

DOI: https://doi.org/10.29271/jcpsp.2020.04.407
At present, there still exists inconsistent conclusions on the POCD incidence between patients with general anesthesia and non-general anesthesia. Therefore, the aim of this paper, is to evaluate and analyse whether the incidence of POCD among postoperative patients is affected by general anesthesia.

\section{METHODOLOGY}

Cochrane Library, PubMed, Medline, WOS and other databases were explored to acquire eligible studies. All the above databases were searched from their inceptive dates up to Sep 2018. A combination of Medical Subheadings (MeSH) and free terms were used to retrieve all the potential articles. The keywords used in literature search included: "postoperative cognitive dysfunction", "POCD", "general anesthesia", "epidural anesthesia", "spinal anesthesia", "nerve block or regional anesthesia". The bibliographies of the included studies were also searched to find other potential ones. All the articles included in this paper were all reviewed and evaluated by three investigators independently.

Articles included in this systematic review were: published, randomized controlled trials (RCTs) and having patients' aged $\geq 18$ years, no mental and neurological diseases, no history of anesthetic allergy, and who had signed informed consent. Articles were excluded, if trials had a sample size smaller than 10 , studies which were reported in scientific meetings, correspondence, case reports, or review papers, duplicate publications, had incomplete information or data. In addition, animal studies and reviews were also excluded. 
Table I. Characteristics of the included studies in the systematic review.

\begin{tabular}{|c|c|c|}
\hline Included studies & Number of patients & Patients with POCD \\
\hline Casati A $2003^{11}$ & $\begin{array}{l}\text { Spinal anesthesia / General Anesthesia } \\
(15 / 15)\end{array}$ & $\begin{array}{l}\text { Postoperative 1d, Spinal anesthesia / General Anesthesia (8/9) } \\
\text { Postoperative 7d, Spinal anesthesia / General Anesthesia (1/3) }\end{array}$ \\
\hline Williams-RP $1995^{12}$ & $\begin{array}{l}\text { Epidural anesthesia / General Anesthesia } \\
(134 / 128)\end{array}$ & Postoperative 7d, Epidural anesthesia/ General Anesthesia (16/12) \\
\hline Shi HJ $2015^{13}$ & $\begin{array}{l}\text { Epidural anesthesia / General Anesthesia } \\
(50 / 50)\end{array}$ & $\begin{array}{l}\text { Postoperative 1d, Epidural anesthesia/ General Anesthesia (8/18) } \\
\text { Postoperative 3d, Epidural anesthesia/ General Anesthesia (3/5) }\end{array}$ \\
\hline Sun YB $2016^{14}$ & $\begin{array}{l}\text { Epidural anesthesia / General Anesthesia } \\
(95 / 98)\end{array}$ & $\begin{array}{l}\text { Postoperative } 1 d \text {, Epidural anesthesia/ General Anesthesia (23/75) } \\
\text { Postoperative 3d, Epidural anesthesia/ General Anesthesia (21/36) }\end{array}$ \\
\hline Silbert BS $2014^{15}$ & $\begin{array}{l}\text { Spinal anesthesia / General Anesthesia } \\
(38 / 49)\end{array}$ & $\begin{array}{l}\text { Postoperative 7d, Spinal anesthesia / General Anesthesia (5/2) } \\
\text { Postoperative 3m, Spinal anesthesia / General Anesthesia (9/3) }\end{array}$ \\
\hline Zhang B $2012^{16}$ & $\begin{array}{l}\text { Spinal anesthesia / General Anesthesia } \\
(15 / 30)\end{array}$ & Postoperative 7d, Spinal anesthesia / General Anesthesia (0/4) \\
\hline Rasmussen LS $2003^{17}$ & $\begin{array}{l}\text { Regional anesthesia / General Anesthesia } \\
(158 / 156)\end{array}$ & $\begin{array}{l}\text { Postoperative 7d, Regional anesthesia/ General Anesthesia (20/33) } \\
\text { Postoperative 3m, Regional anesthesia/ General Anesthesia (21/19) }\end{array}$ \\
\hline
\end{tabular}

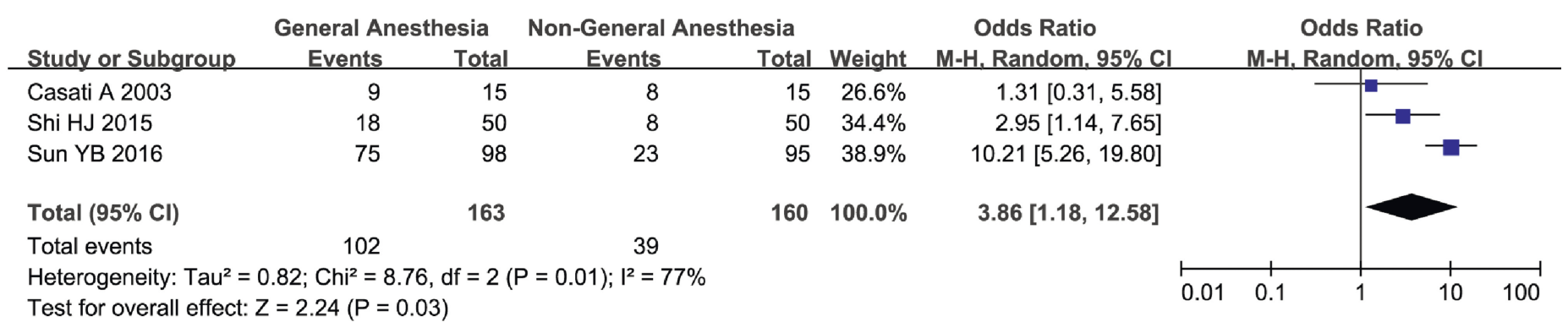

Figure 1: Forest plot of the incidence of POCD between patients with general and non-general anesthesia on the 1st day after surgery.

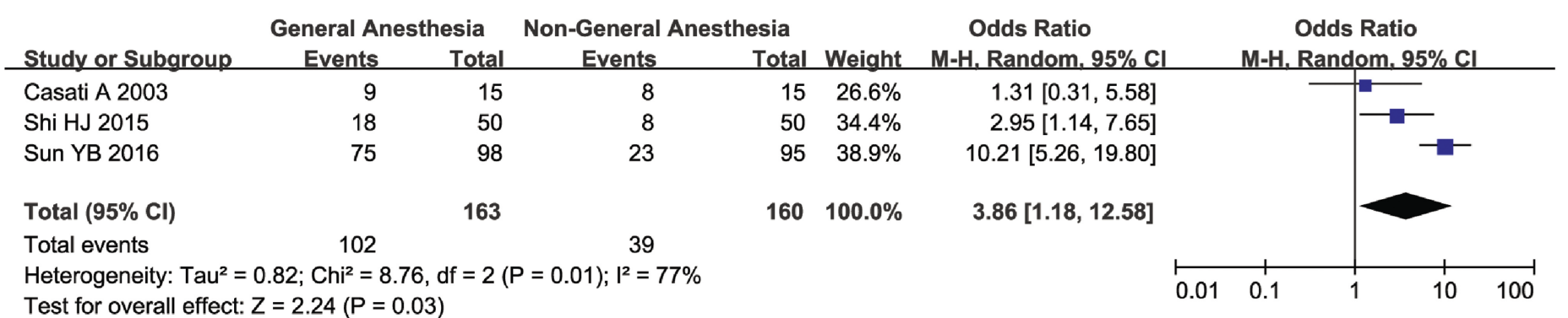

Figure 2: Forest plot of the incidence of POCD between patients with general and non-general anesthesia on the 3rd day after surgery.

\begin{tabular}{|c|c|c|c|c|c|c|c|c|c|c|}
\hline \multirow[b]{2}{*}{ Study or Subgroup } & \multicolumn{2}{|c|}{ General Anesthesia } & \multicolumn{2}{|c|}{ Non-General Anesthesia } & \multirow[b]{2}{*}{ Weight } & \multirow{2}{*}{$\begin{array}{c}\text { Odds Ratio } \\
\text { M-H, Random, } 95 \% \mathrm{Cl}\end{array}$} & \multirow{2}{*}{\multicolumn{3}{|c|}{$\begin{array}{c}\text { Odds Ratio } \\
\text { M-H, Random, } 95 \% \mathrm{Cl}\end{array}$}} & \\
\hline & Events & Total & Events & Total & & & & & & \\
\hline Casati A 2003 & 9 & 15 & 8 & 15 & $26.6 \%$ & $1.31[0.31,5.58]$ & & & & \\
\hline Shi HJ 2015 & 18 & 50 & 8 & 50 & $34.4 \%$ & $2.95[1.14,7.65]$ & & & & \\
\hline Sun YB 2016 & 75 & 98 & 23 & 95 & $38.9 \%$ & $10.21[5.26,19.80]$ & & & & \\
\hline Total $(95 \% \mathrm{Cl})$ & & 163 & & 160 & $100.0 \%$ & $3.86[1.18,12.58]$ & & & & \\
\hline Total events & 102 & & 39 & & & & & & & \\
\hline $\begin{array}{l}\text { Heterogeneity: } \mathrm{Tau}^{2}= \\
\text { Test for overall effect: }\end{array}$ & $\begin{array}{l}.82 ; \mathrm{Chi}^{2}=8 \\
=2.24(\mathrm{P}=\end{array}$ & $=2(\mathrm{~F}$ & $P=0.01) ;\left.\right|^{2}=77 \%$ & & & & 0.01 & 0.1 & 10 & 100 \\
\hline
\end{tabular}

Figure 3: Forest plot of the incidence of POCD between patients with general and non-general anesthesia on the 7th day after surgery. 


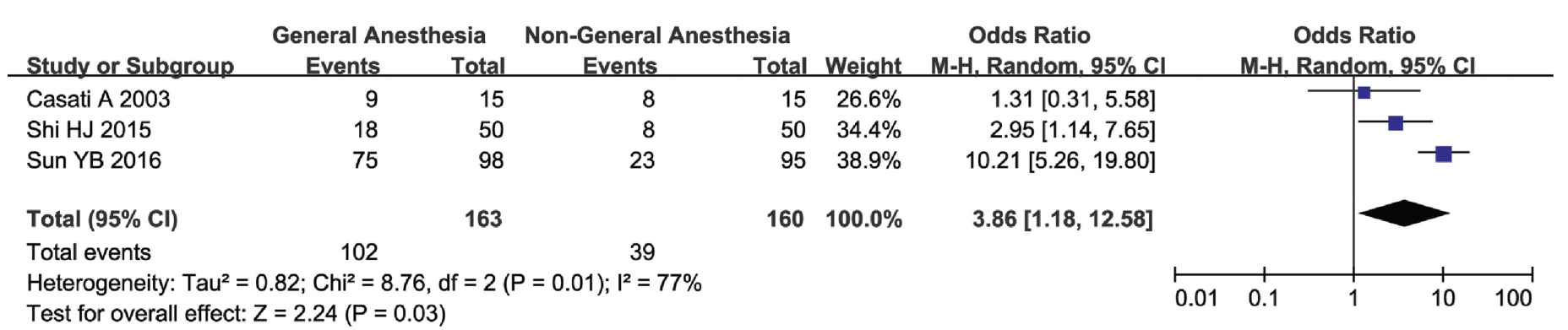

Figure 4: Forest plot of the incidence of POCD between patients with general and non-general anesthesia on the third month after surgery.

All the studies were reviewed by three researchers inde-pendently, based on the criteria for inclusion and exclusion. All the relevant information from the candidate trials, as well as the consistency of the data, were extracted and checked independently by the same reviewers using a standardised data collection form.

Cochrane Collaboration' s tool was used for assessing risk of bias in RCTs, which includes seven items of risk bias (random sequence generation, allocation concealment, blinding of participant and personnel, blinding of outcome assessment, incomplete outcome data, selective reporting and other bias.

Statistical analysis was conducted by using RevMan version 5.2. Data were expressed as odds ratio (OR) and $95 \%$ confidence interval $(\mathrm{Cl}) . I^{2}$ tests was used to test the hetero-geneity among the studies. If $P<0.1, I^{2} \geq 50 \%$ or $P>0.1, I^{2}>50 \%$, it indicated the existence of heterogeneity in the studies, a randomeffects model was then used. A fixed-effects model were to conduct the systematic review when the studies showed no heterogeneity $\left(P>0.1, I^{2}<50 \%\right.$ or $\left.P<0.1 I^{2}<50 \%\right)$.

\section{RESULTS}

Thirty studies were potentially relevant to this search strategy. However, a total of seven studies with 1,031 patients (including 526 patients in general anesthesia group and 505 patients in non-general anesthesia) matched the selection criteria, and were finally included in this systematic review. The characteristics of the included studies were summarised in Table I.

Three studies assessed the incidence of POCD between patients with general anesthesia and non-general anesthesia one day after surgery. ${ }^{11,13}$ Because of heterogeneity among the studies, random-effects model was used for analysis. The results showed that the incidence of POCD in patients underwent general anesthesia was significantly higher than those with non-general anesthesia at one day after surgery $(\mathrm{OR}=3.86,95 \% \mathrm{Cl}=1.18-12.58, p=0.03$, Figure 1$)$.

Two selected studies compared the occurrence of POCD between patients with general anesthesia and non-general anesthesia three days after surgery. ${ }^{13,14}$ The fixed-effects model was used for analysis because there was no heterogeneity between two studies. The results showed that general anesthesia markedly increased the occurrence of POCD in patients as compared with the non-general anesthesia at three days after surgery. $(\mathrm{OR}=2.00,95 \% \mathrm{Cl}=1.11-3.58, p=0.02$, Figure 2).

Five studies evaluated the incidence of POCD between patients with general anesthesia and non-general anesthesia seven days after surgery. ${ }^{11,12,15-17}$ The fixed-effects model was used for analysis due to no heterogeneity in the studies. The results showed that there was no remarkable difference in the incidence of POCD between patients with general anesthesia and non-general anesthesia at seven days after surgery $(\mathrm{OR}=1.29,95 \% \mathrm{Cl}=0.84-1.98, p=0.25$, Figure 3$)$.

Two incorporated studies estimated the occurrence of POCD between patients with general anesthesia and non-general anesthesia three months after surgery. ${ }^{15,17}$ Owing to the heterogeneity between the studies, the random-effects model was used for analysis. The results showed that there was no prominent difference in the occurrence of POCD between patients with general anesthesia and non-general anesthesia at 3 months after surgery $(\mathrm{OR}=0.57,95 \% \mathrm{Cl}=0.17-1.85, p=0.35$, Figure 4).

\section{DISCUSSION}

POCD is a neurodegenerative change, which may induce or aggravate by surgery, anesthesia, and multiple other factors. ${ }^{18}$ POCD is mainly manifested as insanity, anxiety, personality changes and memory impairment. It can even lead to the loss of self-care ability in severe cases, thus causing even more deteriorative postoperative complications, prolonged the duration of hospital stay, and increase social medical expenses. ${ }^{19}$ Therefore, clinician should pay enough attention to the occurrence of POCD in patients after surgery.

However, the pathogenesis of POCD has not been fully clarified, which may be related to increasing age, surgical trauma, narcotic drugs, disease types, and stress response and other factors. ${ }^{20}$ Notably, the relationship between narcotic drugs and the incidence of POCD mainly manifested in the choice of anesthesia methods, whereas there has been a great deal of controversy about the relationship between different anesthesia methods and the incidence of POCD.

Due to lack of a sensitive diagnostic method, a high specificity serum markers or a risk assessment models, POCD is hardly to diagnose. Therefore, the diagnosis of POCD is usually measured by a neuropsychological scale. But there are many different scales, so the results are not always same. ${ }^{21}$ Interna- 
tional study of postoperative cognitive dysfunction (IS-POCD) reported that the incidence of POCD between general anesthesia and spinal anesthesia in the elderly had no significant effect, but patients with general anesthesia showed delayed response to mental activity in 24 hours after surgery. ${ }^{22}$ In addition, other studies demonstrated that the POCD incidence among patients underwent general anesthesia was obviously higher than those underwent spinal anesthesia. ${ }^{23}$ Therefore, the choice of effective and appropriate anesthesia method is one of the great significances' in preventing the occurrence of POCD.

In this paper, we compared the POCD incidence between patients underwent general anesthesia and non-general anesthesia. The results suggested that the incidence of POCD in patients with general anesthesia was significantly higher than those with non-general anesthesia within three days after surgery. However, the occurrence of POCD was not significantly different between patients underwent general anesthesia and non-general anesthesia beyond seven days after surgery. It is suggested that early intervention and treatment in the first three days of operation might be of great value to reduce the incidence of $P O C D$; and patients with high risk of POCD could be recovered quickly after the operation. But at the same time, we should also pay attention to the preoperative education of such patients. ${ }^{18}$

With seven studies included in this systematic review, we used Cochrane Collaborative Network System Evaluation to evaluate the selected literature, and ensure the accuracy and reliability of the analysis. In this study, mini-mental state examination (MMSE) or neuropsychological test was used for the assessment of the patients' cognitive function, so there may exist a subjective bias risk. In addition, some limitations also exist in this systematic review. Firstly, the number of included studies was limited. Secondly, possible language bias could occur because we only included articles in English. Therefore, high-quality RCTs with lager sample need to be designed to further evaluate the difference between the incidence of POCD in patients underwent general anesthesia and non-general anesthesia.

The outcome of this study is credible, it can provide evidencebased medicine reference for clinical practice to some extent. However, owing to the differences in the anesthetisation, and medication and basic physical features of the patients from different countries and zones, the stability of the result may be affected. In addition, evaluating cognitive function during the first three postoperative days may be too early to reflect an actual incidence of POCD as the result of the effect of other factors such as the complications of postoperative infection, the use of benzodiazepine and opioid that may confuse the results of the evaluation. Therefore, what is the best time to assess the cognitive functions before and after surgery is not clear. Thus, the evaluation time point must be ascertained before any definitive conclusion to be drawn from current evidences.
The existing results showed that both the general anesthesia and non-general anesthesia may affect the patient's cognition, leading to the occurrence of POCD. The POCD incidence in patients with general anesthesia is higher than those undergo non-general anesthesia within three days after the surgery. But the POCD incidence was not significantly different between patients undergo general anesthesia or non-general anesthesia seven days after the surgery. Thus, it is suggested that early intervention to the patients with high-risk of POCD should be performed as soon as possible.

\section{CONFLICT OF INTEREST:}

Authors declared no conflict of interest.

\section{AUTHORS' CONTRIBUTION:}

HW: Conceptualised the plan for the current study; assisted in interpreting the results; assessed the data quality and approved the final version of the manuscript for submission.

YG: Did the literature search, screening and data extraction; drafted the manuscript.

LL, BZ: Performed critical appraisal of all included studies.

YW, SY: Analysed data and assisted in the writing of paper. All authors have critically reviewed the manuscript.

\section{ACKNOWLEDGEMENT:}

This work was supported by the National Natural Science Foundation of Hubei (No.2017CFB267) and the Basic Scientific Research Foundation of Central Universities (No.2042 017kf0144).

\section{REFERENCES}

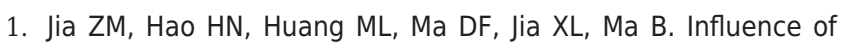
dexmedetomidine to cognitive function during recovery period for children with general anesthesia. Eur Rev Med Pharmacol Sci 2017; 21:1106-11.

2. Skvarc DR, Berk M, Byrne LK, Dean OM, Dodd S, Lewis M, et al. Post-operative cognitive dysfunction an exploration of the inflammatory hypothesis and novel therapies. Neurosci Biobehav Rev 2018; 84:116-33.

3. Verfaillie SCJ, Slot RE, Tijms BM, Bouwman F, Benedictus MR, Overbeek JM, et al. Thinner cortex in patients with subjective cognitive decline is associated with steeper decline of memory. Neurosci Biobehav Rev 2018; 61:238-44.

4. Coppen EM, van Grond J, Hart EP, Lakke EAJF, Roos RAC. The visual cortex and visual cognition in huntington's disease an overview of current literature. Behav Brain Res 2018; 351:63-74.

5. Kim J, Na HK, Byun J, Shin J, Kim S, Lee BH, et al. Tracking cognitive decline in amnestic mild cognitive impairment and early-Stage alzheimer dementia mini-mental state examination versus neuropsychological battery. Dement Geriatr Cogn Disord 2017; 44:105-17.

6. Evered L, Silbert B, Scott DA, Ames D, Maruff P, Blennow K. Cerebrospinal fluid biomarker for alzheimer disease predicts postoperative cognitive dysfunction. Anesthesiology 2016; 124:353-61.

7. Arora SS, Gooch JL, García PS. Postoperative cognitive dysfunction alzheimer's disease and anesthesia. Int J Neurosci 2014; 124:236-42.

8. Steinmetz J, Rasmussen LS. Peri-operative cognitive dysfunction and protection. Anaesthesia 2016; 71:58-63.

\section{CONCLUSION}


9. Tachibana S, Hayase T, Osuda M, Kazuma S, Yamakage M. Recovery of postoperative cognitive function in elderly patients after a long duration of desflurane anesthesia a pilot study. J Anesth 2015; 29:627-30.

10. Guay J. General anaesthesia. Does not contribute to long-term post-operative cognitive dysfunction in adults a meta-analysis. Indian J Anaesth 2011; 55:358-63.

11. Casati A, Aldegheri G, Vinciguerra E, Marsan A, Fraschini G, Torri G. Randomized comparison between sevoflurane anaesthesia and unilateral spinal anaesthesia in elderly patients undergoing orthopaedic surgery. Eur J Anaesthesiol 2003; 20:640-6.

12. Williams-Russo $P$, Sharrock NE, Mattis S, Szatrowski TP Charlson ME. Charlson, cognitive effects after epidural vs general anesthesia in older adults a randomized trial. JAMA 1995; 274:44-50.

13. Shi HJ, Xue XH, Wang YL, Zhang WS, Wang ZS, Yu AL. Effects of different anesthesia methods on cognitive dysfunction after hip replacement operation in elder patients. Int J Clin Exp Med 2015; 8:3883-8.

14. Sun YB, Sun SH, Liu DW, Bai B, Zhang YL, Guo YX, et al. The influence of different anesthesia techniques on cognitive dysfunction in elderly patients. Int J Clin Exp Med 2016; 9:16373-8.

15. Silbert BS, Evered LA, Scott DA. Incidence of postoperative cognitive dysfunction after general or spinal anaesthesia for extracorporeal shock wave lithotripsy. Br J Anaesth 2014; 113:784-91.
16. Zhang B, Tian M, Zhen Y, Yue $Y$, Sherman J, Zheng H, et al. The effects of isoflurane and desflurane on cognitive function in humans. Anesth Analg 2012; 114:410-5.

17. Rasmussen LS, Johnson T, Kuipers HM, Kristensen D, Siersma VD, Vila $P$, et al. Does anaesthesia cause postoperative cognitive dysfunction a randomised study of regional versus general anaesthesia in 438 elderly patients. Acta Anaesthesiol Scand 2003; 47:260-6.

18. Needham MJ, Webb CE, Bryden DC. Bryden, Postoperative cognitive dysfunction and dementia what we need to know and do. BrJ Anaesth 2017; 119:115-25.

19. Jeon YT, Kim BG, Park YH, Sohn HM, Kim J, Kim SC, et al. Postoperative cognitive changes after total knee arthroplasty under regional anesthesia. Medicine (Baltimore) 2016; 95:e5635.

20. Rasmussen LS, Steinmetz J. Ambulatory anaesthesia and cognitive dysfunction. Curr Opin Anaesthesiol 2015; 28: 631-5.

21. Zhang $X$, Dong Q, Fang J. Impacts of general and spinal anaesthesia on short-term cognitive function and mental status in elderly patients undergoing orthopaedic surgery. J Coll Physicians Surg Pak 2019; 29:101-4.

22. Cohendy R, Brougere A, Cuvillon P. Anaesthesia in the older patient. Curr Opin Clin Nutr Metab Care 2005; 8:17-21.

23. Mason SE, Noel-Storr A, Ritchie CW. The impact of general and regional anesthesia on the incidence of post-operative cognitive dysfunction and post-operative delirium a systematic review with meta-analysis. J Alzheimers Dis 2010; 22:67-79. 